\title{
FROM THE EDITORIAL BOARD
}

\section{ZEROING IN ON PERFORMANCE 2.0: FROM SERIALIZATION TO PERFORMATIVE ENACTMENTS}

\author{
Antti Lindfors \\ University of Turku, Finland \\ e-mail:anmili@utu.fi
}

\begin{abstract}
This article explores the notions of performativity and performance in digital environments from the combined perspective of linguistic anthropology and folkloristics. In order to bring these diverging conceptual, methodological, and disciplinary traditions into mutual contact, an intermediary heuristic term of "performative enactments" is introduced. Performative enactments are elaborated as events of communicative sign behavior that foreground and make use of the principle of performativity, although not performances proper in the sense of manifesting a specific "mode of communication" (Bauman 1984). Two different cases of digital communication are analyzed, the first manifesting an instance of everyday SMS messaging between two friends, the second concerning the so-called Per-Looks media event that took place in Finland in October 2012. Both cases are approached as materially durable performative enactments with methodological attention laid on poetic patterning understood as a textually diffuse form of performativity.
\end{abstract}

Keywords: diagraph, enactment, iconicity, irony, linguistic anthropology, parallelism, parody, performance, performativity, poetics, text messaging

One of the mainstays of folkloristic investigations since the $1960 \mathrm{~s}$, not least in the American context, has been a focus on performances, primarily verbal in nature, but increasingly also nonverbal, choreographic, material, visual, technologically mediated, or otherwise. Folklore, verbal art, and other patterned expressive forms and practices are understood as being typically performed for others' emotional and cognitive uptake, evaluation, participation, and possible enjoyment in interactional events specifically "keyed" to highlight responsibility for communicative competence (most notably after Bauman 1984 [1975]). Quite early on, the viewpoint of performance was translated onto what has been termed studies on computer-mediated communication or CMC (e.g. Kirschenblatt-Gimblett 1996), also succinctly rephrased as digital discourse (Thurlow \& Mroczek 2011). However, the specific epistemology of digital performances, 
it seems to me, has been somewhat lacking. First of all, are performances necessarily keyed in digital or text-based environments, and do they constitute a recognizable mode of communication? If they are (not) keyed, how do we signal, recognize, and apprehend them? As importantly, what are the implications of approaching expressive practices in digital environments from the perspectives of performativity and performance as variously understood in linguistics and linguistic anthropology, cultural theory, and folkloristics?

Performativity and performance are by now established keywords and conceptual hubs in various disciplinary fields, and the paradigm of performance studies is somewhat famous for its eclecticism. They are both, however, used in a confusing variety of ways. A disclaimer regarding what we here mean by speaking of performativity and performance, then, is in order at the outset. There are two discursive and disciplinary traditions related to performativity and performances that I would like to explicate here in order to position myself appropriately. Crudely put: firstly, in linguistics and linguistic anthropology, performativity typically refers to a principle of functional efficacy, to the actional aspect of discourse and communicative sign behavior. This tradition has evolved from John Austin's (1962) original meditations on the "illocutionary force" of certain utterances (tokens of the type of speech acts he first labeled as "performatives") onto the current situation, in which performativity is understood as pervasive of all discourse although variating along several intersecting dimensions, such as metapragmatic explicitness, discursive localizability, relative "defeasibility", etc. (Lempert \& Fleming 2014; Duranti 2004). Relatedly, in cultural theory broadly understood, performativity is generally conceptualized as reproduction and reiteration of social and cultural norms: identity and subjectivity as repetitive practices within historical, social, cultural, political, and other constraints (see Barad 2007: 57-66).

Secondly, folklore scholars have typically oriented towards performativity in the context of specifically marked events and a "mode of communication" (Bauman 1984 [1975]: 9), which is further associated with responsibility for communicative competence, as already pointed out. Summarizing the main tenets of the perspective of folkloristics on such performances proper, Simon J. Bronner (2012: 30) notes that "while variations exist in the use of performance, for most American folklorists applying the concept, the important principles are that: folklore is identified as aesthetically marked events (rather than textual items) situated in an observable, specific frame or stage conducive to artistic communication (usually small groups and settings set apart from ordinary life); performers take responsibility for presentation of this artistic material to an audience; performers strategically shape expressions in response to the immediate context and personal motivations, public purposes, and collateral effects; 
and perceptions of the meaning of the performance may vary with different segments of the audience and performers, and in different times and settings, and those perceptions are valid and discoverable in ethnographic observation".

I would like to also add or rather clarify that these performances proper to folkloristic interest - often enacted and analyzed as multimodal configurations - are typically conceptualized as accomplishments of intentional subjects, whereas the relations between intentionality and the principle of performativity remain relatively contested (Bauman 2012; Duranti 2015, esp. chapter 2; cf. also Lloyd 1999; Zwagerman 2010). ${ }^{1}$

The point worth restating here is that whereas performativity refers to a principle (of reiterative efficacy), performance refers to an event or perceivable action (see also Fischer-Lichte (2008), who emphasizes the distinction). That is, the two notions belong to conceptually and logically distinct domains, so that the larger principle of performativity is possibly seen as encompassing singular instances of performance (which, in turn, gather much of their force from performativity). In order to bring these diverging traditions into mutual contact, I will align myself primarily with the aforementioned linguistic anthropological tradition, in order to shed light on certain events or situations of communicative behavior in digital environments that are also interesting for folklore scholars and other analysts of culture and communication - I prefer to call them performative enactments. The significance of generating an intermediary, heuristic term of performative enactments is to leave open the resilient and culturally loaded questions regarding the level of intentionality, agency, responsibility, situational emergence and markedness, as well as aesthetic value associated with various deployments of performativity, which seem to function as primary qualifications of performances proper in the folkloristic tradition. ${ }^{2}$ Performative enactments are thus heuristically understood as events of communicative sign behavior that foreground and make use of the principle of performativity, although not performances proper in the sense of manifesting a specific mode of communication. ${ }^{3}$

Enactment provides a useful and relatively unburdened term for interrogating and problematizing certain contact points as well as differences between the two broad methodological traditions related to performativity and performance. Like performance, enactment refers to events and action, but in the sense of typically foregrounding decentralized, networked, or diffuse agency as well as indeterminate or extended temporality. As such, the notion of enactment can be particularly useful in approaching communicative events in digital environments that inscribe (verbal) communication as durable, visual trace to be apprehended by interlocutors. Insofar as digital communication foregrounds durable materiality and thus potentially calibrates or extends the temporality 
of communicative events (Buccitelli 2012: 75-78), digital environments seem to provide specific grounds for the scaffolding of performative enactments. What is more, enactment orients us toward performative assemblages between human and non-human actors, such as technological, material, and discursive objects. For Maria Schwertl (2016: 169), who draws from post-actor-network theorist Annemarie Mol, "enactment is a way to look at practices while looking at humans and objects" insofar as enactment forms "the conjuncture of diverse human and non-human actors who interact to create the situation and its entities or objects".

My argument is twofold. Firstly, I suggest that when studying performative enactments in digital environments, folklorists have to apprehend and engage with the principle of performativity theorized in linguistic anthropology. In short, this is the type of performativity that renders speech behavior and communication into effective action and can be hypothesized as also constituting the "micro-level" of performances proper. Accordingly, this route makes it hypothetically possible to detect and problematize specific folkloric performance practices that might be characteristic for digital environments.

Secondly, I will underscore that an important key to approach performative enactments in digital environments is constituted by poetics, and poetic parallelism in particular. Poetics is here designated as a function of communicative sign behavior, in which the performative efficacy of an instance of semiosis is amplified by reflexive juxtaposition of co-textual units of utterance. Poetics is thus one form of performativity, characterized as highly distributed and textually diffuse in its formal organization (Lempert \& Fleming 2014), and presumably a very productive one in digital environments for reasons explicated below. As known, Roman Jakobson (1960) originally characterized the poetic function of language very broadly as sequential juxtaposition of corresponding units of utterance within a compositional whole, i.e., as phonetical, grammatical, or syntactic units, words, symbolic articulations, or even structural or narrative sequences that are understood as indexing each other co-textually (Pressman 1994: 471; Glick 2012; cf. Tannen 2007 [1989]: 9). ${ }^{4}$ The significance of adopting the concept here is, however, to use it as a specific and folkloristically sensible gateway into the discussions of performativity, which in analysis is usefully complemented by related terms such as dialogic resonance, parallelism, and metapragmatic iconicity. These complementary terms will be introduced and explicated at appropriate places during the analysis. 


\section{DIGITAL AFFORDANCES FOR POETICS AND PERFORMATIVITY}

In an article on digital performances as seen from the perspective of folkloristics - performance 2.0 in the author's coinage - Anthony Buccitelli (2012: 78) lists "serialization" as one of the characteristic principles of digital discursive interaction. By serialization he refers to the fact that in digital environments, including traditional discussion forums, instant messaging, social networking sites such as Facebook, Instagram, and Youtube, singular messages are by necessity discrete and sequentially positioned one after another. Buccitelli writes:

In contrast to a face-to-face context, where there is often room for overlapping or intersecting forms of speech, action, or expression by different participants, the structure of the technological environment in which many digital performances occur requires that such expressions take place sequentially rather than in direct juxtaposition. Text, audio, or video posts, however close together they are published, are inherently serialized on the web in the order that they were submitted to the server. (ibid., emphasis mine)

Serialization as described by Buccitelli can be understood as a contribution to the discussion underlining the analytical import of communicative affordances with respect to technological media. Derived from an interaction between individual's subjective perception of utility and objective qualities of a technology - be that a paint brush or a cell phone - affordances refer to the fact that these technologies "afford certain communicative possibilities and not others" (Thurlow \& Mroczek 2011: xxiv; Schrock 2015; cf. Hutchby 2001). In other words, the communicative medium and its affordances are seen as having a reality of its own for interlocutors, irrespective of whether they consciously apprehend its effect or explicitly describe it. ${ }^{5}$

I would like to use Buccitelli's insight, which I think is valid and worth expanding on, as a jumping off point, elaborating on, and offering a few contributions to it. The aim is to demonstrate how an important portion of performative enactments in digital environments rely on emergent co-textual patterning that can be approached under the heading of poetics. When addressing poetics in aesthetically unmarked discourse, however, it is methodologically essential to realize that various poetic juxtapositions and affinities arise in digital and face-to-face environments all the time. There is always a veritable "surfeit of poetic patterns", an excess of possibly efficacious affinities and contrasts in communication, which have to be apprehended, restrained, and circumscribed in interaction for them to become socially meaningful (Lempert \& Fleming 2014). 
As folklorists, when speaking of performativity and performing, then, it becomes crucial to look into how these poetic patterns and the sort of small-scale reflexivity apparent in all interactions are calibrated and taken over socially by interactional agents. For whom do these poetic patterns actually decode as meaningful, performative effects, to what degree, and why? The last interrogative moreover points to how we simultaneously need to account for notions such as context and situation, participative agency, and efficacy, all crucial aspects of what is understood by performativity and performance (see also Pratt 1977 [1975]).

Ideally, one should also consider and compare the notions of performativity, performative enactments, and performances proper across all kinds of channels, modalities, textures, and means of communication available in digital environments (see also Buccitelli 2012: 79-80; Harper 2010: 6). For instance, it has been argued that identities in interactive social media, the so-called Web 2.0, are inexorably managed and thus performed. The same problematic is also brought forward by Buccitelli's (2012) anecdote opening his article, by which he recounts an incident in which his friend had deleted his Facebook account, as he felt the latter "forced" him to become a (narcissistic) performer of sorts. By my reckoning, the anecdote implicates that insofar as digital environments seem to omit explicit cues of keying and framing, it becomes essential to question how certain communicative platforms - for example, playfully oriented forums or, indeed, Facebook - might themselves foreground or coerce frames of performance, or otherwise elicit concerns of heightened performativity. They might achieve this by staging discrete texts as public expressions of seemingly authentic selves, which further take part in social practices of interpersonal evaluation and attention management: think of Facebook with its built-in devices for various affective reactions (see Paasonen 2016). Or, we might inquire into the potentials of more complex websites to perform in various ways: websites have several tactics at their disposal to perform in socially consequential manner, such as creative layout design, framing, etc. (see, e.g., Foley 2012; also Bogost 2010 on "visual rhetoric").

While such a full-scale comparative study is naturally beyond the scope of this text, I will supplement my initial focus on text-based digital interaction (SMS texting, instant messaging, etc.) with a second case that deals with what could be called visual poetics. What is more, I believe my general thesis regarding performative enactments is applicable for various other forms of digital communication, such as the use of emoticons, image memes, and hyperlinks, insofar as they are similarly functional in creating emergent effects in relation to their co(n)textual environments. Sequentially juxtaposed emoticons and image memes are, however, often even more ambiguous than verbalized messages, which means that their specific performative and pragmatic effects in various contexts might be more difficult to pin down (see also Milner 2013: 65). 


\section{TEXT-BASED DIGITAL ENVIRONMENTS}

Whereas the orientation of performance heralded an approach in folkloristics that laid the stress on entextualization, paralinguistics, and gestural dimensions of communicative enactments, a recurring topic in digital studies relates to how the significance of these dimensions of discursive interaction seems to have become diminished if not effaced in text-based environments. To say the least, the (somewhat limiting) affordance of communicating through the single channel of the visible writing system calls for a reconsideration of our epistemologies of performing. ${ }^{6}$ As mentioned, folkloristic studies on performing have been driven by the Baumanian spirit that regards performances as explicitly keyed as somehow distinct from other, unmarked communicative forms (see Bauman 1984 [1975]: 15-24, for conventional methods of keying in oral discourse). Needless to say, explicit keyings also occur in text-based digital environments. For instance, Tuija Virtanen (2013) has coined the term of "discourse transformers", by which she refers to discourse markers that signal shifts to different frames in digital discourse. Her specific focus is on "mock performatives" signaled by the formal marker hereby in text-based digital communication ("You are hereby banished from this kingdom!"), which she observes as typically initiating joint play sequences between interlocutors. However, whereas hereby as studied by Virtanen constitutes an explicit keying of playfulness, such explicit signals are often lacking in (digital) interaction.

To address the question of how we recognize performative enactments lacking explicit keying in text-based digital environments, I propose to turn to the potentials of implicit keying provided by poetic patterning. Poetic patterning is predicated as a highly productive constituent of performative enactments in digital environments insofar as the latter intrinsically self-organize around serialized, discrete units of utterance. In this regard, we should pay closer attention to the mutual match between poetics and text-based digital communication, because by necessity, for us to recognize the reflexively juxtaposed units responsible for poetic effects, we need certain formal instructions. What is needed, in particular, is some form of sequentiality of textual organization. And I suggest it is the cutting up of the otherwise linear discursive signal as a tendency of digital communication - serialization as per Buccitelli (2012) - that should be seen as functional in orienting us toward the poetic comparability of co-occurring, but not immediately contiguous, units in relation to each other and the whole textual event (Agha 1997: 469). 


\section{Poetics at Play in SMS Communication}

The first example that I would like to look at brings forward an instance of SMS text messaging in which the performativity of poetic patterning is implemented in everyday interaction by both interlocutors. Deborah Tannen (2013) provides this thought-provoking example of dyadic SMS texting event in her article on metamessages inherent to various communicative media, and analyses the case herself primarily from the perspective of formal stylization: the use of intensity markers and taciturnity. Tannen recounts an event provided to her by one of her students, in which Jackie and her friends gathered together in order to go somewhere. "As everyone in the group piled into taxis, only Jackie was left awaiting a last member of the group, who had been delayed." Left stranded by her friends, Jackie sent one of her departed friends in the taxis the text message represented in her first turn of dialogue (line 1). The following interactional sequence ensued (Tannen 2013: 108-109):

(1) 1

Jackie: Thanks for waiting for Melissa with me that's cool

2 Friend: JACKIE I AM SO SO SO SORRY! I thought you were behind us in the cab and then I saw you weren't!!!!!

I feel soooooooo bad! Catch another cab and ill pay for it for youuuuu

$3 \quad$ Jackie: no its fine we are walking

$4 \quad$ Friend: seriously Jackie please, get a cab, I feel so bad!!!

$5 \quad$ Jackie: we are walking there its fine

To summarize, Tannen (ibid.) describes how Jackie uses taciturnity to send a negative metamessage, that is, how her terse messages conspicuously lack any expressive markers, indicating how less than "fine" she really felt about the situation. On the other hand, Jackie's friend adopts various formal devices - expressive spelling, capitalization, repetition, reduplicated punctuation - to send a metamessage of affective intensity along with her explicit message of apology. ${ }^{7}$

To add to Tannen's analysis from the perspective that we have been elaborating on, we might note how SMS texting serializes singular messages and renders visible the sequentiality of textual organization for interlocutors on their mobile phones. ${ }^{8}$ To begin with, then, of importance is how Jackie initiates the interactional sequence by recourse to the expressive form of irony (line 1). Presumably provoked by disappointment, her mock-performative of thanking her friend for a (non-existent) act and predicating this course of action as "cool" is taken to implicate a negative comment on her friend's (lack of) considerateness. Her friend apprehends the ironic intention by apologizing intensely, explicating her (sincere or not) personal viewpoint on the preceding situation, 
denoting a negative affective state, which implicates a stance of regret, and by suggesting a correction to the dire situation.

Cues for poetic resonance appear in line 3. Propositionally speaking, Jackie's terse "no its fine we are walking" predicates an affective stance of neutrality, and a description of an (ongoing) course of action - it remains undecided whether her "fine" refers to the state of events or to her own affective stance. The stance of neutrality is corroborated by her laconic form of expression, as also noted by Tannen. On a superficial interpersonal level, Jackie thus notionally aligns herself with her interlocutor-friend. From a broader interactional perspective, however, things look different. Juxtaposed with the first, prominently ironic line, this third line is seen as resonating with it, and hence connoting, updating, and adding to the ironic effect: the overtone of neutrality is subordinated by an undertone of disappointment or displeasure with the chain of events.

Resonance is a concept used by sociolinguist John W. Du Bois, which he defines as "activated affinities across utterances or representations"; it is thus a property of relations between elements of discourse, not an isolatable attribute. Du Bois uses resonance as a complementary term for studying co-produced conversational discourse from the perspective of reproduction of utterance elements in general and poetic parallelisms in particular. Parallelism, for its part, can be designated as a type of recurrence or repetition with difference "in which parallel units are perceived as parallel members of groups" (Frog forthcoming; also Lindfors forthcoming). Thus, resonance creates relations between utterance elements, while parallelism is a product of producing such relations and thus a manifestation of the broader category of resonance (Du Bois 2014: 372-375). In order to map such reproduced elements, structures, and emergent resonances across utterances, Du Bois $(2007,2014)$ has developed a highly flexible "diagraph model" which allows one to organize dialogically juxtaposed utterance elements on a grid for visual rendering. In the present case, the diagraph (modeled after Du Bois 2014) can be deployed for bringing out the parallelism between Jackie's first two turns of dialogue (corresponding units of utterance are visually indicated by shading of the boxes):

(2)

\begin{tabular}{|c|c|c|c|}
\hline 1 Jackie: & Thanks for waiting for Melissa with me th & 's cool & \\
\hline ackie: & it & 's fine & we are walking \\
\hline
\end{tabular}

Even though not salient between whole turns of dialogue, activated resonance and parallelism are here salient on the level of individual sentences. That is, in line 3, Jackie repeats her previous sentence "that's cool" with variation on the lexical surface (“it's fine"), producing the ironic effect identified earlier. Her second turn is dependent on the intermediate contrasting stance of her 
interlocutor, and thus simultaneously both responsive to her friend's apology and paralleling her own previous sentence. ${ }^{9}$

Revealingly, her friend is seen to recognize and apprehend this poetically produced and textually diffuse ironic effect in responding with an even more earnest plea ("seriously Jackie please"), which indicates that she has not bought Jackie's initial riposte represented in line 3 , but sensed more to be at play. The performativity of Jackie's poetic patterning is thus signaled, apprehended, and felt - there also seems to be a heightened engagement of participants in the situation (see Ling 2008, chapter 6).

What is more, the friend's two turns of dialogue in themselves manifest a form of resonance, rhetorical chiasmus to be specific, in which two units of utterance are repeated in an inverse sequence:

(3)

\begin{tabular}{|c|c|c|c|c|}
\hline 2 Friend: & $\ldots$ & I feel soooooooo bad! & Catch another cab & $\begin{array}{l}\text { and ill pay for } \\
\text { it for youuuuu }\end{array}$ \\
\hline 4 Friend: & $\begin{array}{l}\text { Seriously } \\
\text { Jackie please }\end{array}$ & get a cab & I feel so bad!!! & \\
\hline
\end{tabular}

Importantly in the sense that both interlocutors can be now observed as patterning their discourse poetically, not much new propositional information is produced: the conversation seems to have become somewhat stagnated in a standstill through repetitions and parallelisms on both sides. Performative and social tension, however, is still intact and very much felt. On top of this, Jackie's final response (line 5) constitutes yet another instance of salient resonance. By basically reproducing the exact same phrases as in line 3 - although in an inverse syntactical sequence, thus also exhibiting a rhetorical chiasmus Jackie further corroborates her stance of apparent neutrality and superficial alignment with her interlocutor. This chiasmus in turn resonates with, and may even be prompted by (see Sakita 2006 on emergent parallelism in syntax), her friend's chiasmus noted earlier, throwing into relief the pervasive intertwining of poetic resonance through the interactional sequence. The recurring ironic effect is again felt to be at play, the final turn of dialogue bringing home and settling the resolute nature of Jackie's disalignment with her friend in an even more conspicuously foregrounded fashion. By the end of the interactional sequence, Jackie is attributed a resolution of stance - perhaps a stance of firm disappointment. It could even be argued that, had she intended to convey sincere neutrality in line 5 , this intention is belied by the emergent, coercive pull of the actualized parallelism (cf. Glick 2012).

I would like to finally draw attention to how a bridge from poetic patterning in discourse to performative enactments can be built through the notion 
of metapragmatic effects. As Lempert \& Fleming (2014: 490) explain, poetic patterning "may come to guide an interpretation of what is being done in the text, of what acts people are doing, what roles people are inhabiting, what definition of the situation is in progress", and further note how such guidelines are typically the performative effect of metapragmatic iconicity (see also Silverstein 2004). To clarify, iconic resemblance between utterance elements in sequentially metricalized text - which is a semiotic way of framing parallelism - is understood as producing metapragmatic effects with regard to the communicative action at hand. In this case, the iconicity between units of utterance across three turns of dialogue produces the emergent metapragmatic effect of communicating the speaker's unyielding and resolute stance with regard to the preceding events. Jackie does not merely repeat with minor variations; her action is not merely a function of likeness or unlikeness between separate turns of dialogue. Rather, what is enacted through poetic iconicity is a cumulative effect or inference: the resolution of stance vis-à-vis her friend's apologies and appeals, or a "reluctance to let her friend off the hook", as Tannen (2013: 109) so aptly puts it. ${ }^{10}$ Iconic resemblance and repetition here have an all-encompassing effect on interpretations regarding action, participation roles, and definition of the situation. The point is, however, that the significance of this iconic pattern cannot be conflated with the significance of the utterances through which the iconic pattern is produced and achieved. Rather, poetic iconicity provides the grounds for comparison of utterance units, while comparison "in respect of what speakers say then serves as a principle for interpreting what speakers do" (Lempert \& Fleming 2014: 489).

I suggest it is preferable to term such communicative instances, in which the inherent performativity of poetic patterning is emphasized and deployed in (digital) discursive interaction, performative enactments. These enactments do not manifest a specific mode of communication, which would qualify them as performances proper in the sense that has been the tradition in folkloristics this tradition is, of course, somewhat expected because the focus in the latter has been primarily on specialized uses of language, such as verbal art, ritual speech, etc. That is, Jackie does not adopt a marked mode of performance, nor is she seen as claiming responsibility for specific communicative competence. Such enactments are, rather, events of communicative sign behavior that foreground and make use of the principle of performativity, for instance in the form of dialogic resonance, parallelisms, and metapragmatic iconicity, to enact and pursue distinct interactional outcomes. Performative enactments are, moreover, typically achieved cumulatively, for instance, over several turns-of-talk, which means that researchers should accordingly pay closer attention to the provisional and cumulative nature of such enactments in interaction (Lempert 
\& Fleming 2014: 492). Insofar as these enactments are apprehended and thus only efficient in acts of interpretative construal, it is always possible for the interactional agents responsible for interpretative acts to "get" them only partially, or, to get them in completely different ways. This is something that has to be kept in mind when theorizing poetically produced performativity online, which re-emerges with our second case in an illustrative manner.

\section{VISUAL WEB DESIGN AS PERFORMATIVE ENACTMENT: THE PER-LOOKS MEDIA EVENT IN FINLAND}

The second example that I would like to present concerns a case in which a visually oriented website - albeit a simple one - is understood as implementing performative effects. I am referring to the so-called Per-Looks media event that took place in the Finnish media over a few days of October 2012 and quickly generated a surge of heated online debate. Per-Looks is a website, still available online for the reader to see (that is, in November 2016), which is simply comprised of its eponymous logo in the top corner, rows and columns of photographic portraits of the Finns Party municipal election candidates, and pretty much nothing else (formerly known as the True Finns - "Perussuomalaiset" in Finnish; the title Per-Looks is thus derived, to be clear, from the first three letters of the party's Finnish name). This photographic gallery was uploaded and introduced on the social photograph-sharing media Tumblr on the 7th of October 2012, and maintained its status as a hot topic in the Finnish media spotlights for a few days before vanishing into oblivion. The site gave rise to columns, news articles, blog texts, Facebook debates, and forum discussions across party lines, a lion's share of which focused on the site's putative meanings, functions, implications, tastefulness, etc. Heated debate took place due to the fact that even though the website itself presented itself as conspicuously and seemingly neutral, a strong line of interpretation took it as maliciously intentioned mockery targeting the habitus of the Finns Party candidates, which was further associated with the lower class.

As background information regarding the debate around Per-Looks, it should be pointed out that one salient divide in the Finnish social and political climate - even more so after the general elections of 2015 - is situated between the ("Green-Left") liberal urban and the conservative provincial social fraction, the latter of which is prominently represented by the Finns Party. The efficacy of the Per-Looks website was related to the fact that it struck the Finnish social and political imagination by juxtaposing and conflating these two opposing (very coarsely speaking, of course) social and political fractions, identities, 
and habitus. It also bears mentioning that similar galleries of the candidates of other Finnish political parties quickly emerged after the Per-Looks event. However, none of these derivations garnered as much (negative) attention from the public as the original.

I want to clarify at the outset that my intention here is not to (moralistically) address the issue of whether the website was distasteful or not, nor whether it manifested a stable "message" that could be potentially peeled out by supposedly authoritative analytics: these were the issues interlocutors themselves in various online forums contested vigorously. Rather, by treading the path laid out in previous chapters, I aim to outline an analytic perspective to the website as (an ambiguous) performative enactment dependent on poetic patterning. After all, the Per-Looks website was interpreted by commentators and interlocutors as first and foremost performing socially, most prominently as enacting insult. It was not regarded as visually representing the candidates as if representation could ever be neutral or stable in a semiotic sense: this much is proven, by my reckoning, by the empirical fact that people were offended by the website. By commencing from this basic observation, I intend to show how the performative aspects of the website were a function of its poetic design - again, understood as formal patterning that reflexively draws attention to co-present similarities and differences by juxtaposition.

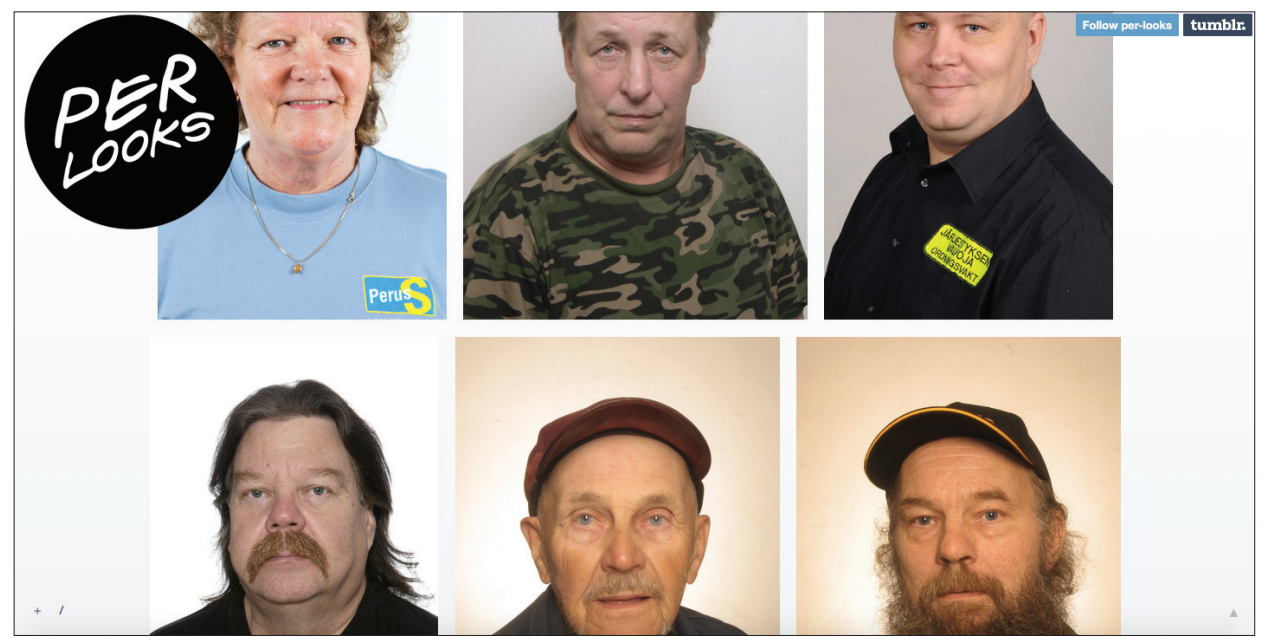

Figure 1. Screenshot of the Per-Looks website (http://per-looks.tumblr.com/). 
As said, the website is a simple gallery comprised of a selection of photographic portraits of the populist Finns Party candidates for the 2012 municipal elections (see Fig. 1). While the images themselves are official promotional photographs of the said political party, echoing similar galleries usually seen on sidewalks before elections, they are collated side-by-side, row after row, without captions or any verbal commentary whatsoever. That is, the webpage is deliberately designed so as to abstain from prescriptive metacommentary, from commenting on the intentions and aims motivating the website or the actual display of the photographs. However, such "conceit of neutrality" (Walton \& Jaffe 2011) is belied by the singular and most prominent contextualization cue of the site: the title of the gallery. The title Per-Looks is phrased after the popular website Hel-Looks, a style and fashion site documenting the latest street fashion of Helsinki (http://www.hel-looks.com/). In addition to the verbal pun itself, this imitative intention is brought home by the visual design of the logo, likewise reminiscent and modelled after the Hel-Looks logo. The gallery thus exhibits explicit "recipient design" (Sacks \& Schegloff \& Jefferson 1974), a purposive steering of attention to the differential between the source (Hel-Looks) and the target (Per-Looks) (see Lempert 2014).

Further implications emerge out of these objective features of the website. As an imitation or parody of Hel-Looks, outer appearance, style, fashion, and taste ("-Looks") are foregrounded in the portraits of the candidates as dominant orienting frames. Indeed, the political candidates are individualized according to the tradition of portraiture, a genre of visual discourse that in itself can be seen as reflecting an indelible interest in the articulation of human variety. For instance, Mieke Bal notes how portraiture foregrounds individuality in an inherently contrastive framework, because "it also provides tools with which to speak of the sameness in difference and the difference in sameness, both at once" (Bal 2002: 229). Further still, insofar as the photographs are collated on the website after what must have been a process of deliberate selection perhaps hand-picked out of hundreds of potential choices - the representation of the candidates does not seem random but more reasonably construed as following certain logic. Rather than trying to evaluate here the motivations of this logic, I find it preferable to turn to the public interpretations that the website gave rise to.

The imitative nature of Per-Looks was widely recognized in the ensuing reactive commentary in the (social) media. It also seemed as though an ironic or mocking intent was attributed to the website by most commentators - however, the explicit terms of humor, parody, irony, and sarcasm were, not unexpectedly, used rather loosely and impressionistically. In a representative news article, the motivating purpose of the gallery was regarded as "most probably to joke 
around to the detriment of the candidates of the Finns Party", even though the parodying intent that supposedly also targeted the Hel-Looks brand was simultaneously recognized (see Uusi Suomi 2012). ${ }^{11}$ In other words, the target and the implications of this ironic mocking emerged as a focal bone of contestation from which other deductions followed. One line of interpretation suggested how the outer appearance of the Finns Party candidates as portrayed by Per-Looks was a positive one, notwithstanding the (possibly malicious) motivations of its author. This viewpoint was crystallized, for example, in the following comment:

Whatever the mischievous author of the Tumblr had intentioned when compiling his collection, he has unintentionally created a catalogue that is productive in arousing sympathies towards the Finns Party. Through these various faces the party gives off just the kinds of mental images that they presumably want to give: ordinariness and unaffectedness. [...] the authenticity and humanity of these common candidates shines through the photographs spontaneously. ${ }^{12}$

Of course, parody and other forms of deliberately ambiguous expression are distinct in that they are structured so as to obscure precisely these aspects of communication. They can appear as manifesting a seemingly "neutral" stance, or, better yet, juxtaposing, superimposing, and playing with several stances, simultaneously indexing multiplicities of both stances and audiences. And by indexing multiple stances, all of those stances are rendered potentially available to be claimed after the fact by the stance-taker (Jaffe 2009: 18).

For the purposes of the present article, I want to draw attention to how the website was understood and claimed as issuing a generalization of social types. To borrow from recent studies on semiotic registers, the gallery was construed as enregistering a specific "Finns Party register", in the sense of a certain model of personhood, which in this case articulated a political fraction with (negative) associations of style, fashion, taste, and habitus. ${ }^{13}$ Even though I will sidestep any attempt at a detailed analysis of the specific diacritics of appearance, taste, or habitus of Per-Looks in the following, it is obvious that these visual diacritics were ultimately also perceived as emblematic of lower social class (see Helsingin Sanomat 2012).

Enregisterment here refers to the process by which semiotic registers are metasemiotically formed, while registers' repertoires have to be understood as comprising a full range of semiotic modalities, "signs in any phenomenal channel of perceivable conduct" (Agha 2011: 26; Agha 2007; Agha \& Frog 2015). As Frog explains, "rather than being restricted to resources and conventions appropriate to certain situations of linguistic behavior, a register can be viewed more comprehensively as resources constitutive of cultural 'models of action", 
including resources such as outer appearance, habitus, taste, behavior, etc. (Frog 2014: 199, citing Agha 2007: 81). What was more, the Per-Looks website was construed as indexing this register in both senses of the word, entailing and presupposing, the latter of which was presumably more socially efficacious (e.g. offensive). In other words, it gave rise to and entailed the object as well as insinuated about the factual existence of this supposedly known social type.

Enregisterment can be analyzed as a general process that precipitates over a longer sequence of time (Agha 2007, chapter 4), but also as an enactment of briefer temporal span (e.g. Johnstone 2011). In this case, it is fruitful to approach it through the notion of enactment that can be analyzed from the perspectives of both the website and of secondary interpretative construal. In the following, I will concentrate on the former. I suggest the website accomplishes the enregisterment of a social type by framing itself as a fashion gallery, but also by its formally poetic features that foreground co-present similarities and differences through parallelism.

Perhaps most important of these features is how the website lays the individual photographs in serialized rows, the number of photographs in which varies, though, in relation to the size of the browser window as well as in relation to the width of the photographs (not all of them are of the exact same size). The photographs are formally and thematically comparable: they depict persons in frontal portraits and headshots. Given the basic presumption that the website is approached as an entextualized whole, constituted of distinguishable units of meaningful expression (photographic images), this patterning has the effect of formatting the presentation so that the parallelism between individual photographs becomes highly salient. To borrow from Jakobson's (1960) seminal formulation of poetics, we can say that the website accomplishes a shift of focus onto the level of sequential positioning within a compositional whole, or alternatively that the text exhibits a high level of diagrammatic motivation (see Lempert 2008: 573). Parallelism articulates a mapping between dialogically juxtaposed units of expression with the consequence that the photographs are interpreted as iconically similar and indexing each other: they become comparable vis-à-vis their mutual (proposed) likeness and unlikeness. In this case, the dominant reference frame of Hel-Looks is of primary significance with regard to which features of the photographs come into focus in considerations of likeness and unlikeness. This frame structures the reception of Per-Looks by correlating the series of photographs of political candidates with representations of style, taste, or fashion.

In sum, the efficacy of Per-Looks as performative enactment derives from the saturated parallelism of formally and thematically comparable visual units subsumed under the dominant reference frame of "looks". The website manifests 
indexical iconicity between serialized images, which reflexively draws attention to its own form and content and gives rise to a higher-level (interpretative) process that I have here captured with the semiotic notion of enregisterment. Enregisterment thus refers to how the diacritics of appearance, style, and taste are made to appear as indexically congruent, as indexing a stable model of personhood and an emblem of social class, while congruence here is a function of poetic parallelism. However, while the correlation of titles of Per-Looks (as the target) and Hel-Looks (as the source and reference frame) provides the recipients with the most obvious instructions to approach the photographs as representations of style or fashion, the precise communicative action accomplished by the website is never explicitly described or referred to. Rather, the reflexive function associated with parallelism serves as a principle for the construal of meaningful communication, and can be, again, conceptualized through metapragmatic iconicity (Lempert 2008: 573). This ambiguous enactment was then interpreted through a diverse scale as pejorative "mockery", "parody", etc., by acts of attribution from the interpreters' part.

As a final point regarding the ambiguous nature of poetically accomplished performative enactments, it is worth noting how the reception of these enactments can be revealing with regard to the recipients (interpreters) themselves. Accordingly, Per-Looks was also understood as functioning in the way of a Rorschach test for the society to reveal its ideological assumptions in the nexus of different political parties, classes, and appearances. In the words of an online commenter: "In addition to that (probably by accident) it [Per-Looks website] is quite an ingenious mirror; You can say quite a lot about a person by looking at how he or she reacts to it - especially if you can compare it with some precedent." 14 The commenter here recognizes and explicates one of the characteristic features of poetically accomplished performative enactments: the nature of their effects as emergent and ephemeral projections that can be perfectly functional and justifiable in determinate contexts but that remain fundamentally contestable.

\section{FROM SERIALIZATION TO PERFORMATIVE ENACTMENTS}

In this article, I have laid out an approach to performative enactments in digital environments useful for both linguistic anthropologists and folklorists alike. Just as poetics has been deemed ubiquitous if fleeting in discursive interaction, I suggest folklorists interested in performances and performative enactments in digital environments have to orient themselves to the more general performativity that is emergent and empirically retraceable in everyday digital 
interaction (see also Buccitelli 2012: 68). The larger argument of my paper, then, relates to the fact that poetically accomplished performative enactments may be much more frequent and commonplace than we perhaps might have at first thought (this point is also stated through parallelism in Glick 2012). This might be increasingly relevant, given the one-dimensional monomodality and the foregrounded materiality of technologically mediated (textual) communication. After all, performing does not have to be multimodally intricate, instantly and unequivocally recognizable, or explicitly keyed.

First, I analyzed a sequence of SMS text messaging between two friends (provided by Tannen 2013) and showed how the dialogically resonant patterning of both interlocutors comes to convey metapragmatic effects through iconicity. In this way, performative enactments might be said to deploy poetic patterning to do something more, to give rise to various inferences and effects by constructing metapragmatic icons (Lempert \& Fleming 2014: 490). While listing a full inventory of such metapragmatic icons could prove futile or impossible in the abstract, it remains an important task for folklorists and linguistic anthropologists to analyze the functions of these moves in concrete ethnographic settings and contexts. Another point of the analysis was to demonstrate that the strictly propositional level of the text - the referring and the predicating played out in each separate utterance - constitutes only a fraction, albeit in a sense the backbone, of interaction. This level is most conspicuous to overt inspection, especially in text-based digital environments, which render the propositional text overtly visible as durable, material trace. However, it gets us only so far with regard to the complete interactive dynamics in general, as well as to performativity in particular.

Secondly, I presented the case of the Per-Looks media event that took place in Finland some years ago. My intention with this case was to show how poetics and performativity as communicative principles can be operationalized as valuable tools to also approach visual discourse and web design. I argued how the formal and thematic parallelism articulated between individual portraits on the website, along with its conspicuous title, implemented a semiotic process called enregisterment, in which a specific cultural model of personhood emerged. In short, the website reframed the original election photographs into a textual configuration that came to foreground the visual diacritics of appearance, fashion, taste, and habitus as social indexicals of a supposed type. Again, the performative enactment was seen as an outcome of the reflexive patterning of units of meaningful expression within an entextualized whole, i.e., the website. The uptake of this implicit enactment was then vigorously contested in diverse, and highly revealing, interpretations by various commenters. Performative 
enactments have the power to elicit participative engagement of their recipients, to draw them in (cf. Collins 2004 on what he calls "entrainment"). The recipient, in recognizing an enactment, typically signals apprehension of the said enactment by reacting to it, which was also seen in both of the examples. Such reactions often constitute the most visible or perceivable semiotic proof of the effect of performative enactments.

The so-called mobile society of the twenty-first century has been seen as implementing fundamental changes in the way we keep in touch with each other, express ourselves, as well as form and sustain communities across places and times. According to certain commenters, there has been a veritable shift "from fixed geographies of sociality to dynamic spatial flows of human interaction" (Harper 2010: 113). Be that as it may, Danet (2005), amongst others (e.g. Couldry 2003), has shown how with some provisos and adaption, tried and tested ethnographic methods are still appropriate for studying mediated, performative, and ritualized interaction online. This sanguine hypothesis has also served as the guiding star for the present article, and I believe it will continue to provide digital scholars with an ethnographic bent with plenty of work in the future.

\section{ACKNOWLEDGEMENTS}

The first draft of this paper was prepared for the Folklore Fellows' Summer School held in Seili, Nauvo, in June 2015. Besides the participants of the Summer School and anonymous reviewers provided by the journal Folklore: Electronic Journal of Folklore, I would like to thank Mr. Frog from the University of Helsinki for crucial help with a later draft of this paper.

\section{NOTES}

1 Bearing these distinctions in mind, it is curious how normatively Don Kulick (2003), linguistic anthropologist himself, wants to deny performativity the status of a linguistic concept on the fact that it originally emerged in philosophy. By his estimate, linguistic anthropology has mostly studied various performances, not performativity. For Kulick (2003: 140), "performance is something a subject does. Performativity, on the other hand, is the process through which the subject emerges (Butler 1993: 2, 7, 95)." In aligning himself with what I have termed the perspective of cultural theory, Kulick's exclusive formulation that focuses on the emergence of subjectivity tends to dismiss crucial work in linguistic anthropology, where the significance of performativity has to be understood as something like "causal efficacy of signs in society" (Lempert \& Fleming 2014: 495). 
2 Interestingly, Maria Schwertl (2016) has recently proposed "enactment" as an intermediary term between the notions of performance and practice, the former of which is primarily associated with American folkloristics, and the latter with European ethnology. For Schwertl (2016: 173), enactment offers sensitivity towards both "the usual activity" (habitual practice) and "the something that will perhaps matter" (emergent performance). For a classic discussion of enactments in folklore studies, see Abrahams 1977.

3 Granted, Judith Butler (1990: 44, 89; also Butler 1997: 21, 44) already approached performativity through the notion of enactment, for instance, by defining sex as "a performatively enacted signification" and gender "as an enactment that performatively constitutes the appearance of its own interior fixity" (see also Schwertl 2016: 174, footnote 3). My approach differs from hers in conceptualizing the performative aspect of language use through its specific implementation through poetics, to be elaborated below.

${ }^{4}$ Although emphasized in emic genres specifically designated as "poetic", the poetic function has generally been regarded as, if not too frequently demonstrated to be, a pervasive feature of all discourse (Banti \& Giannattasio 2004; for a detailed case of conversational poetics, see Glick 2012). By my reckoning, the abstract principle of poetics is thus to specific genres of poetries as performativity is to specific performances. That is to say, poetics and performativity are the necessary principles of poetries and performances, while the latter implement and make use of the former in specific, socioculturally and historically contingent ways (see also Lempert \& Fleming 2014: 505 , footnote 3 ).

5 The notion of affordances could be productively interrogated with the idea of metamessages inherent to different media platforms (Tannen 2013). For instance, on some occasions the fact that you will phone your friend instead of texting him or her carries significant implicit meaning in itself, just as writing a letter vs. typing it carried similar connotations some decades ago. The values attached to different technological media have to be further understood as inter-generational and -cultural phenomena (see also Höflich \& Gebhardt 2006).

6 On the other hand, monomodality of text-based environments can be argued as turning the participants' attention specifically to the verbal means of their interaction by reducing the transparency of their communicative means (e.g. Georgakopoulou 2003). Interestingly, such metalinguistic foregrounding has also been suggested as highlighting the import of explicit metadiscourse and as encouraging verbal play such as figurative language use and various voicing phenomena. Georgakopoulou (2003) further interprets it as encouraging the putting on of various personae (see also Danet 2001; Kramer 2011: 140-141).

7 It might be illuminating to note here that insofar as texting is relatively cumbersome and time-consuming, tendencies and strategies to save time, effort, and space are frequently observed in SMS messaging, as are immediacy and informality of style. Furthermore, SMS "messages are addressed to specific individuals with a high degree of personal disclosure", which means that SMS messengers typically have a high degree of insight into each other's lives and personas (Hård af Segerstad 2006: 35). 
8 It was of course Tannen herself (2007 [1989]; see also Lempert 2008: 572), who originally took issue with identifying and demonstrating the poetic qualities of conversational discourse, and my intention is not to contest or disqualify Tannen's own analysis regarding this sequence of SMS interaction by any means.

9 The stance of apparent neutrality that she maintains vis-à-vis the unfortunate event of abandonment and her friend by the parallelism - and against which her friend also positions herself, although contrastively - could be also described through the notion of deixis (see Frog forthcoming for a discussion of deixis in relation to parallelism).

10 To borrow Tannen some more from her seminal work on repetition in conversational discourse, repetition foregrounds and intensifies the part repeated, while also paradoxically foregrounding and intensifying the part that is different (2007 [1989]: 60-61). To repeat is rarely just a repetition of the same; rather, the audience "reinterprets the meaning of the word or phrase in light of the accretion, juxtaposition, or expansion" (ibid.: 62). Here, what is different is a function of the cumulative effect itself.

${ }^{11}$ In a one-of-a-kind interview, the author of the gallery, graphic artist Juha Leinonen, was referenced as saying how the intention behind the website was precisely to mock the original website Hel-Looks and the "cultures of posing and showing off" it is alleged as representing. According to him, the page did not further any political agenda (see Helsingin Sanomat 2012). The case illustrates particularly poignantly how speakers in general have "contextually variable access to and authority over the illocutionary force of their own utterances" (Duranti 2015: 4).

12 Original in Finnish: "Mitä sitten lieneekään pilkkamielinen tumblrintekijä ajatellut kokoelmaansa laatiessaan, hän on tahtomattaan tullut luoneeksi kuvaston joka on omiaan herättämään sympatiaa perussuomalaisia kohtaan. Näiden kaikenlaisten kasvojen kautta puolue antaa itsestään juuri sellaisia mielikuvia joita todennäköisesti haluaisikin antaa: kansanomaisuutta ja teeskentelemättömyyttä. [...] näiden riviehdokkaiden aitous ja ihmisyys paistavat kuvista välittöminä” (see Harran 2012).

${ }^{13}$ Put differently, the Per-Looks website rendered the election photographs into commodity formulations. Commodity formulations foreground certain products or objects clothing, outer appearance, etc. - as social indexicals, "as objects whose use indexes attributes of users that differentiates them from others within frameworks of social classification" (Agha 2011: 24).

${ }^{14}$ Original in Finnish: "Sen lisäksi se (todennäköisesti vahingossa) on varsin näppärä peili; Voit kertoa ihmisestä aika paljon sen perusteella, miten hän reagoi siihen etenkin jos voit verrata sitä johonkin aikaisempaan" (see comment \#3 in Harran 2012). 


\section{REFERENCES}

Abrahams, Roger D. 1977. Toward an Enactment-Centered Theory of Folklore. In: William R. Bascom (ed.) Frontiers of Folklore. Boulder, CO: published by Westview Press for the American Association for the Advancement of Science, pp. 79-120.

Agha, Asif 1997. Tropic Aggression in the Clinton-Dole Presidential Debate. Pragmatics, Vol. 7, No. 4, pp. 461-497. Available at http://journals.linguisticsociety.org/ elanguage/pragmatics/article/download/252/252-537-1-PB.pdf, last accessed on June 30, 2017.

Agha, Asif 2007. Language and Social Relations. Cambridge: Cambridge University Press.

Agha, Asif 2011. Commodity Registers. Journal of Linguistic Anthropology, Vol. 21, No. 1, pp. 22-53. http://dx.doi.org/10.1111/j.1548-1395.2011.01081.x.

Agha, Asif \& Frog (eds.) 2015. Registers of Communication. Helsinki: Finnish Literature Society.

Austin, John L. 1962. How to Do Things with Words. Edited by J. O. Urmson. London: Clarendon Press.

Bal, Mieke 2002. Travelling Concepts in the Humanities: A Rough Guide. Toronto: University of Toronto Press.

Banti, Georgio \& Giannattasio, Francesco 2004. Poetry. In: Alessandro Duranti (ed.) A Companion to Linguistic Anthropology. Malden, MA: Blackwell, pp. 290-320.

Barad, Karen 2007. Meeting the Universe Halfway: Quantum Physics and the Entanglement of Matter and Meaning. Durham \& London: Duke University Press.

Bauman, Richard 1984 [1975]. Verbal Art as Performance. With supplementary essays by Barbara A. Babcock [and others]. Prospect Heights, Ill.: Waveland Press.

Bauman, Richard 2012. Performance. In: Regina F. Bendix \& Galit Hasan-Rokem (eds.) A Companion to Folklore. Malden: Wiley-Blackwell, pp. 94-118.

Bogost, Ian 2010. Persuasive Games: The Expressive Power of Videogames. Cambridge: MIT Press.

Bronner, Simon J. 2012. Practice Theory in Folklore and Folklife Studies. Folklore, Vol. 123, No. 1, pp. 23-47. http://dx.doi.org/10.1080/0015587X.2012.642985.

Buccitelli, Anthony Bak 2012. Performance 2.0: Observations Toward a Theory of the Digital Performance of Folklore. In: Trevor J. Black (ed.) Folk Culture in the Digital Age: The Emergent Dynamics of Human Interaction. Boulder, CO: Utah State University Press, pp. 60-84.

Butler, Judith 1990. Gender Trouble: Feminism and the Subversion of Identity. New York: Routledge.

Butler, Judith 1993. Bodies That Matter: On the Discursive Limits of "Sex". New York \& London: Routledge.

Butler, Judith 1997. Excitable Speech: A Politics of the Performative. New York \& London: Routledge.

Collins, Randall 2004. Interaction Ritual Chains. Princeton, NJ: Princeton University Press.

Couldry, Nick 2003. Media Rituals: A Critical Approach. London \& New York: Routledge. 
Danet, Brenda 2001. Cyberpl@y: Communicating Online. Oxford: Berg.

Danet, Brenda 2005. Ritualized Play, Art, and Communication on Internet Relay Chat. In: Eric W. Rothenbuhler \& Mihai Coman (eds.) Media Anthropology. Thousand Oaks, CA: SAGE, pp. 229-246.

Du Bois, John W. 2007. The Stance Triangle. In: Robert Englebretson (ed.) Stancetaking in Discourse: Subjectivity, Evaluation, Interaction. Philadelphia: John Benjamins, pp. 139-182.

Du Bois, John W. 2014. Towards a Dialogic Syntax. Cognitive Linguistics, Vol. 25, No. 3, pp. 359-410. http://dx.doi.org/10.1515/cog-2014-0024.

Duranti, Alessandro 2004. Agency in Language. In: Alessandro Duranti (ed.) A Companion to Linguistic Anthropology. Malden, MA: Blackwell, pp. 451-473.

Duranti, Alessandro 2015. The Anthropology of Intentions: Language in a World of Others. Cambridge: Cambridge University Press.

Fischer-Lichte, Erika 2008. The Transformative Power of Performance: A New Aesthetics. Transl. by Saskya Iris Jain. London: Routledge.

Foley, John Miles 2012. Oral Tradition and the Internet: Pathways of the Mind. Urbana: University of Illinois Press.

Frog 2014. Parallelism, Mode, Medium, and Orders of Representation. In: Frog (ed.) Parallelism in Verbal Art and Performance. Pre-Print Papers of the SeminarWorkshop, 26th-27th May 2014, Helsinki, Finland. Helsinki: Folklore Studies, University of Helsinki, pp. 185-207.

Frog (forthcoming). Parallelism and Orders of Signification (Parallelism Dynamics I). Oral Tradition.

Georgakopoulou, Alexandra 2003. Computer-Mediated Communication. In: Jef Verschueren \& Jan-Ola Östman \& Jan Blommaert \& Chris Bulcaen (eds.) Handbook of Pragmatics. Amsterdam \& Philadelphia: John Benjamins.

Glick, Douglas J. 2012. Language Contextualization in a Hebrew Language Television Interview: Lessons from a Semiotic Return to Context. Semiotica, Vol. 192, pp. 341-380. http://dx.doi.org/10.1515/sem-2012-0070.

Hård af Segerstad, Ylva 2006. Language in SMS - A Socio-Linguistic View. In: R. Harper \& L. Palen \& A. Taylor (eds.) The Inside Text: Social, Cultural, and Design Perspectives on SMS. Dordrecht: Springer, pp. 33-51. Available at http://www.springer. com/gp/book/9781402030598, last accessed on June 30, 2017.

Harper, Richard H. R. 2010. Texture: Human Expression in the Age of Communications Overload. Cambridge, Massachusetts: The MIT Press.

Harran, Anis 2012. Perluukkikausti. Uusi Suomi, October 8. Available at http://harran. puheenvuoro.uusisuomi.fi/119854-perluukkikausti, last accessed on June 30, 2017.

Helsingin Sanomat 2012 = Professori: Per Looks -kohun taustalla kysymys luokkayhteiskunnasta. [Professor: The Question of Class Society Lies behind the Commotion on Per Looks.] Helsingin Sanomat, October 10. Available at http://www. hs.fi/kulttuuri/a1305605600646, last accessed on June 30, 2017. 
Höflich, Joachim R. \& Gebhardt, Julian 2006. Changing Cultures of Written Communication: Letter - E-mail - SMS. In: R. Harper \& L. Palen \& A. Taylor (eds.) The Inside Text: Social, Cultural, and Design Perspectives on SMS. Dordrecht: Springer, pp. 9-31. Available at http://www.springer.com/gp/book/9781402030598, last accessed on June 30, 2017.

Hutchby, Ian 2001. Technologies, Texts, and Affordances. Sociology, Vol. 35, No. 2, pp. 441-456. http://dx.doi.org/10.1177/S0038038501000219.

Jaffe, Alexandra 2009. Introduction: The Sociolinguistics of Stance. In: Alexandra Jaffe (ed.) Stance: Sociolinguistic Perspectives. Oxford \& New York: Oxford University Press, pp. 3-28.

Jakobson, Roman 1960. Closing Statement: Linguistics and Poetics. In: Thomas A. Sebeok (ed.) Style in Language. Cambridge, MA: MIT Press, pp. 350-377.

Johnstone, Barbara 2011. Dialect Enregisterment in Performance. Journal of Sociolinguistics, Vol. 15, No. 5, pp. 657-679. DOI: 10.1111/j.1467-9841.2011.00512.x.

Kirschenblatt-Gimblett, Barbara 1996. The Electronic Vernacular. In: George E. Marcus (ed.) Connected: Engagements with Media. Chicago \& London: University of Chicago Press, pp. 21-66.

Kramer, Elise 2011. The Playful Is Political: The Metapragmatics of Internet RapeJoke Arguments. Language in Society, Vol. 40, No. 2, pp. 137-168. http://dx.doi. org/10.1017/S0047404511000017.

Kulick, Don 2003. No. Language \& Communication, Vol. 23, No. 2, pp. 139-151. Available at http://www.sciencedirect.com/science/journal/02715309/23/2, last accessed on June 30, 2017.

Lempert, Michael 2008. The Poetics of Stance: Text-Metricality, Epistemicity, Interaction. Language in Society, Vol. 37, No. 4, pp. 569-592. http://dx.doi.org/10.1017/ S0047404508080779.

Lempert, Michael 2014. Imitation. Annual Review of Anthropology, Vol. 43, No. 1, pp. 379-395. http://dx.doi.org/10.1146/annurev-anthro-102313-030008.

Lempert, Michael \& Fleming, Luke 2014. Poetics and Performativity. In: N. J. Enfield \& Paul Kockelman \& Jack Sidnell (eds.) The Cambridge Handbook of Linguistic Anthropology. Cambridge: Cambridge University Press, pp. 485-515.

Lindfors, Antti (forthcoming). Twin Constellations: Parallelism and Stance in Stand-Up Comedy. Oral Tradition.

Ling, Richard 2008. New Tech, New Ties: How Mobile Communication is Reshaping Social Cohesion. Cambridge, MA: The MIT Press.

Lloyd, Moya 1999. Performativity, Parody, Politics. In: Vikki Bell (ed.) Performativity and Belonging. London: SAGE, pp. 195-213.

Milner, Ryan M. 2013. Hacking the Social: Internet Memes, Identity Antagonism, and the Logic of the Lulz. The Fibreculture Journal, Vol. 22. Available at http:// twentytwo.fibreculturejournal.org/fcj-156-hacking-the-social-internet-memesidentity-antagonism-and-the-logic-of-lulz/, last accessed on July 3, 2017.

Paasonen, Susanna 2016. Fickle Focus: Distraction, Affect, and the Production of Value in Social Media. First Monday, Vol. 21, No. 10. http://dx.doi.org/10.5210/ fm.v21i10.6949. 
Pratt, Mary Louise 1977 [1975]. Toward a Speech Act Theory of Literary Discourse. Bloomington: Indiana University Press.

Pressman, Jon F. 1994. Pragmatics in the Late Twentieth Century: Countering Recent Historiographic Neglect. Pragmatics, Vol. 4, No. 4, pp. 461-489. http://dx.doi. org/10.1075/prag.4.4.06pre.

Sacks, Harvey \& Schegloff, Emanuel A. \& Jefferson, Gail 1974. A Simplest Systematics for the Organization of Turn-Taking for Conversation. Language, Vol. 50, No. 4, pp. 696-735. http://dx.doi.org/10.1353/lan.1974.0010.

Sakita, Tomoko I. 2006. Parallelism in Conversation: Resonance, Schematization, and Extension from the Perspective of Dialogic Syntax and Cognitive Linguistics. Pragmatics and Cognition, Vol. 14, No. 3, pp. 467-500. http://dx.doi.org/10.1075/ pc.14.3.03sak.

Schrock, Andrew Richard 2015. Communicative Affordances of Mobile Media: Portability, Availability, Locatability, and Multimediality. International Journal of Communication, Vol. 9, pp. 1229-1246. Available at http://ijoc.org/index.php/ ijoc/article/view/3288, last accessed on July 3, 2017.

Schwertl, Maria 2016. Response: “We have a situation here!”: On Enactment as a Middle Ground Between Practice and Performance. Cultural Analysis, Vol. 15, No. 1, pp. 168-177. Available at http://socrates.berkeley.edu/ caforum/volume15/vol15_ schwertl.html, last accessed on July 3, 2017.

Silverstein, Michael 2004. "Cultural" Concepts and the Language-Culture Nexus. Current Anthropology, Vol. 45, No. 5, pp. 621-652. http://dx.doi.org/10.1086/423971.

Tannen, Deborah 2007 [1989]. Talking Voices: Repetition, Dialogue, and Imagery in Conversational Discourse. Second Edition. New York: Cambridge University Press.

Tannen, Deborah 2013. The Medium is the Metamessage: Conversational Style in New Media Interaction. In: Deborah Tannen \& Anna Marie Trester (eds.) Discourse 2.0: Language and New Media. Washington, DC: Georgetown University Press, pp. 99-118.

Thurlow, Crispin \& Mroczek, Kristine 2011. Introduction: Fresh Perspectives on New Media Sociolinguistics. In: Crispin Thurlow \& Kristine Mroczek (eds.) Digital Discourse: Language in the New Media. New York: Oxford University Press, pp. xix-xliv.

Uusi Soumi 2012 = Netti-ilmiö hassuttelee perussuomalaisilla: "Katso silmiin". [WebBased Phenomenon Making a Fuss in Finnish: "Look in Your Eyes".] Uusi Suomi, October 7. Available at http://www.uusisuomi.fi/kotimaa/54016-netti-ilmiohassuttelee-perussuomalaisilla-katso-silmiin, last accessed on June 30, 2017.

Virtanen, Tuija 2013. Mock Performatives in Online Discussion Boards. Towards a Discourse-Pragmatic Model of Computer-Mediated Communication. In: Deborah Tannen \& Anne Marie Trester (eds.) Discourse 2.0: Language and New Media. Washington, DC: Georgetown University Press, pp. 155-166.

Walton, Shana \& Jaffe, Alexandra 2011. "Stuff White People Like": Stance, Class, Race, and Internet Commentary. In: Crispin Thurlow \& Kristine Mroczek (eds.) Digital Discourse: Language in the New Media. New York: Oxford University Press, pp. 199-219. 
Wilson, Jason \& Fuller, Glen \& McCrea, Christian 2013. Editorial: Troll Theory? The Fibreculture Journal, Vol. 22, pp. 1-14. Available at http://twentytwo. fibreculturejournal.org/, last accessed on July 3, 2017.

Zwagerman, Sean 2010. Wit's End: Women's Humor as Rhetorical and Performative Strategy. Pittsburgh: University of Pittsburgh Press. 